\title{
Studies on Cultural, Morphological and Biochemical Aspects of Colletotrichum acutatum of Aglaonema using Various Carbon Sources
}

\author{
Tushnima Chaudhuri*, Birendranath Panja and Jayanta Saha
}

Department of Plant Pathology, Faculty of Agriculture, B.C.K.V., Mohanpur, Nadia, West Bengal, India

*Corresponding author

\begin{tabular}{|l|}
\hline Ke y w o r d s \\
Aglaonema, \\
$\begin{array}{l}\text { Colletotrichum } \\
\text { acutatum, Czepek's } \\
\text { Dox agar, Peptone } \\
\text { salt agar, Oat meal } \\
\text { agars }\end{array}$ \\
\hline Article Info \\
\hline $\begin{array}{l}\text { Accepted: } \\
\text { 15 July 2018 } \\
\text { Available Online: } \\
\text { 10 August } 2018\end{array}$ \\
\hline
\end{tabular}

\section{Introduction}

The genus "Aglaonema" is derived from the Greek words "aglos" meaning bright and "nema" meaning thread. These are evergreen perennial herbs with stems growing erect or decumbent and creeping. Stems that grow along the ground may root at the nodes. There is generally a crown of wide
Aglaonema, also called Chinese evergreen, is a popular and low-maintenance houseplant, which not only beautifies our home but also promotes healthier lives by cleaning pollutants from the air. Taking into consideration all these points, the demand for ornamental plants is increasing gradually. The foliage which is considered as the economic part is attacked by different diseases. The various cultural and morphological characteristics of Colletotrichum acutatum from Aglaonema were studied which were grown on different carbon containing media. Out of six carbon sources viz. Potato dextrose agar (PDA), Peptone salt agar (PSA), Czepek's Dox Agar (CDA), dextrose in CDA medium was replaced by the same amount of sucrose (CDASWS) and lactose (CDASWL) and Oat meal agar (OMA) used for the radial growth of the fungus, it was evident that the most effective medium for rapid growth of Colletotrichum acutatum was on PSA medium followed by CDA and CDASWS media. The rate of growth was highest in PSA medium where it attained full growth in $144 \mathrm{hrs}$ of incubation. Significant difference was noted in the dimensions of acervuli, setae and conidia with regards to change in media constituents, wherein it shows that OMA medium produces acervuli, conidia, setae of higher dimensions. The bioassay of three non-systemic fungicides viz. Blitox, Mancozeb and Chlorothalonil and one systemic fungicide Difenoconazole using six different concentrations along with control were examined. It was found that Difenoconazole exhibited the highest percent inhibition at EC50 value of $7.907 \mu / \mathrm{ml}$ and lowest percent inhibition in case of Blitox with a EC50 value of $223.4 \mu / \mathrm{ml}$. 
including India (Bannerjee, 2016; Katakam, 2016).The members of Deuteromycetes including pycnidia producing pathogens (Form order Sphaeropsidales) and acervuli producing pathogens (Form Order Melanconiales) play a major role for destruction of plant parts rapidly by infecting different parts along with production of various ranges of symptoms on plant. Different media are used for various groups of fungi that influence the vegetative growth, colony morphology, pigmentation and sporulation depending upon the composition of specific culture medium, $\mathrm{pH}$, temperature and light (Northolt and Bullerman, 1982; Kuhn and Ghannoum, 2003; Kumara and Rawal, 2008). Physical and chemical factors have a pronounced effect on diagnostic characters of fungi. Hence, it is necessary to use several media while attempting to identify a fungus in culture since mycelial growth and sporulation on artificial media are important biological characteristics. Furthermore, findings for one species are not readily extrapolated to others, particularly for filamentous fungi, where significant morphological and physiological variations exist. Thus, there is the need of testing of different media. Carbon and nitrogen sources and their concentrations bear a significant effect on the type of cultural growth of fungi on the media. Modification of the basal concentrations of these nutrients affects the viability and enzyme production of fungi. Several workers have recognized the importance of spores as inoculum and studies have been conducted on the effects of various media components along with important physiological parameters that lead to maximum sporulation (Kim et al., 2005). So, the use of carbon and nitrogen in the medium needs to be emphasized. Biomass production of a fungus either in solid or liquid medium is an important parameter to judge its efficiency in the utilization of nutrients from the medium i.e. the better the efficiency in utilization, the better will be the production of biomass. It is a good indicator to evaluate the suitability of a medium for growth and maintenance of the fungus, varies according to the types of fungi, species, sub-species or isolates of a fungus and could be a vital parameter for genus/ species/isolate level morphological differentiation. For that reason, recoding of biomass is being emphasized. After isolation, characterization and identification, the evaluation of fungicide sensitivity is a vital exercise in order to find out the efficacies of various fungicides and their doses which can be used for the management of diseases of the above mentioned ornamental plants and help in reduction of crop loss.

\section{Materials and Methods}

The experimental studies like characterization of cultural and morphological parameters using various carbon and nitrogen sources and determinations of fungicide sensitivities of the collected fungi was conducted under laboratory condition of the Department of Plant Pathology of the University. Synthetic, semi-synthetic and natural media were used for various laboratory studies and for the maintenance of plant pathogenic fungus. For studying radial growth, colony morphology and asexual fruit bodies (pycnidia) using various carbon sources like potato dextrose agar (PDA),Czapek's Dox agar (CDA) where dextrose was replaced by the same amount of sucrose(CDASWS) and lactose(CDASWL) per $1000 \mathrm{ml}$ of growth medium,oat meal agar (OMA), water agar (WA) and peptone salt agar (PSA) media were used whereas broth of all these media were used for studying biomass production. Micro-photograph of all the fungal structures in different carbon sources were taken with the help of Leica Binocular Microscope and or Karl Zeis Phase Contrast Microscope(under 10x,40x) and by using Canon Powers Shot A640 camera. Dimensions (e.g. length and breadth) of 
conidia, hyphae, acervulus of fungi were measured using AxioVision (Rel. 4.8.) software.

Sensitivities of the fungus Colletotrichum acutatum to four different fungicides having five different concentrations were tested invitro following poisoned food technique proposed by Shervelle (1979). Different concentrations of fungicides were taken from stock solution with the help of sterilized micro tips which was then mixed with sterilized, molten PDA media before plating to obtain the desired concentrations of active ingredient. A total of three non-systemic viz. Blitox 50 WP, Indofil M-45 and chlorothalonil and one systemic fungicide Score $25 \mathrm{EC}$ was used as four treatments in the fungicide bioassay experiment (Table 1). Radial growth of the various fungi on different concentration and control was recorded. Extent of inhibition of mycelia growth by each fungicide was calculated by estimating the percent reduction in mean mycelial radial growth over that of control (Vincent,1947). Effective concentration for $50 \%$ growth inhibition (EC50 ) by the fungicides for each fungus was determined by plotting the log values of the fungicide concentration against the probit values of percent inhibition on a log-probit scale (Horsefall,1956). A regression equation $\mathrm{Y}=\mathrm{a}+\mathrm{bx}(\mathrm{Y}=$ antilog of concentration of the fungicide, $x=$ probit value of percent inhibition, $\quad b=$ regression co- efficient/ slope, $\mathrm{a}=$ intercepts) was worked out and the fitness of the equation was judged comparing the level of significance with the simple correlation coefficient (r) value at $5 \%$ or $1 \%$ level. Per cent inhibition was measured with the formula, which is given below -

Radial growth in control(C)-Radial growth in treatment(T) x 100

Per cent inhibition $=\frac{\text { Radial growth in } \operatorname{control}(\mathrm{C})}{\text { Ration }}$

\section{Results and Discussion}

The cultural characteristics of the fungi on six different carbon sources were studied with a view to identify the best media for the radial growth and sporulation of the fungi. Out of six carbon sources viz. PDA, PSA, CDA, CDA supplemented with sucrose (CDASWS),CDA with lactose (CDASWL) and OMA used for the radial growth of the fungus, it was evident that the radial growth represented by Colletotrichum acutatum was faster on PSA medium followed by $\mathrm{CDA}$ and CDASWS media. The fungal growth rate was studied with an objective to find out the speed of growth of a particular fungus at a particular point of time. The rate of growth the fungus was highest in PSA medium where it attained full growth in $144 \mathrm{hrs}$ of incubation. The biomass production by the fungus was also studied after $144 \mathrm{hrs}$ of incubation. The fungus
Colletotrichum acutatum exhibited highest biomass in the medium containing PDA followed by CDASWS.

\section{Colony morphological studies}

Colony morphology, colour of the colony from the upper and lower sides of all the four fungus were also studied using the different carbon sources. The objective of the study was to identify the variation in different genus and species of the fungi.

The mycelia of Colletotrichum acutatum were moderately thick to thick, cottony, fluffy mycelium in all the media viz. PDA, CDASWS, CDA and CDASWL with clear variation wherein it produced acervulus in the media containing PSA and OMA. (Plate 1AF). 


\section{Microscopic characteristic studies}

The microscopic characters relating to the dimensions of hyphae, acervuli, setae and conidia were also recorded with a view to see whether there was any marked difference in the dimension of hyphae, acervuli, conidia with regard to changes in media constituents. On the PSA medium, acervuli were produced by Colletotrichum acutatum in huge number.
Hyphae were hyaline thin, septate $8.8-15.7 \mu$

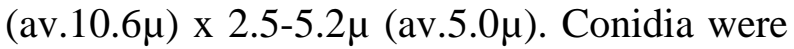
hyaline, single celled, eguttulate, fusiform, broad at centre and tapered at ends (rounded tips) with 1 or 2 longitudinal striation, 11.5 $18.4 \mu$ (av. $10.6 \mu) \times 6.0-10.0 \mu$ (av. $7.3 \mu$ ) in dimension (Plate -2a). The acervuli were

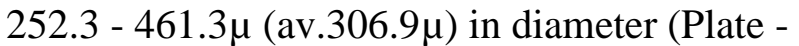
2b), black and dot like.

Table.1 Trade-chemical-,IUPAC- and manufacturer names along with the concentrations of the test fungicides

\begin{tabular}{|l|l|l|l|l|}
\hline Trade name & Chemical name(formula) & IUPAC name & Manufacturer & $\begin{array}{l}\text { Concentrations }(\mu \mathrm{g} / \mathrm{m} \\
\text { 1) used }\end{array}$ \\
\hline Blitox 50 WP & $\begin{array}{l}\text { Copperoxychloride } \\
\left(\mathrm{Cl}_{2} \mathrm{Cu} \mathrm{H}_{2} \mathrm{O}_{3}\right)\end{array}$ & $\begin{array}{l}\text { Dicopper dichloride } \\
\text { trihydroxide. }\end{array}$ & Tata Rallis & $0,10,25,50,100,200$ \\
\hline Indofil M- 45 & $\begin{array}{l}\text { Mancozeb(Polymeric mixture } \\
\text { of Mn and } \mathrm{Zn})\end{array}$ & $\begin{array}{l}\text { Manganese } \\
\text { ethylenebis } \\
\text { (dithiocarbamate) }\end{array}$ & Indofil & $0,10,25,50,100,200$ \\
\hline $\begin{array}{l}\text { Kavach } \mathbf{7 5} \\
\text { WP }\end{array}$ & Chlorothalonil $\left(\mathrm{C}_{8} \mathrm{Cl}_{4} \mathrm{~N}_{2}\right)$ & $\begin{array}{l}2,4,5,6- \\
\text { Tetrachloroisophth-- } \\
\text { alonitrile }\end{array}$ & $\begin{array}{l}\text { Kenvos Biotech } \\
\text { Co., Ltd. }\end{array}$ & $0,10,25,50,100,200$ \\
\hline Score 25 EC & $\begin{array}{l}\text { Difenoconazole } \\
\left(\mathrm{C} 19 \mathrm{H}_{17} \mathrm{Cl}_{2} \mathrm{~N}_{3} \mathrm{O}_{3}\right)\end{array}$ & $\begin{array}{l}\text {-(2-(2-Chloro-4- } \\
\text { (4chlorophenoxy)ph } \\
\text { enyl)-4-methyl-1,3- } \\
\text { dioxolan-2- } \\
\text { yl)methyl)-1H-1,2,4- } \\
\text { triazole }\end{array}$ & Syngenta & $0,10,25,50,100,200$ \\
\hline
\end{tabular}

Plate.1 Colony characteristics in various carbon containing media
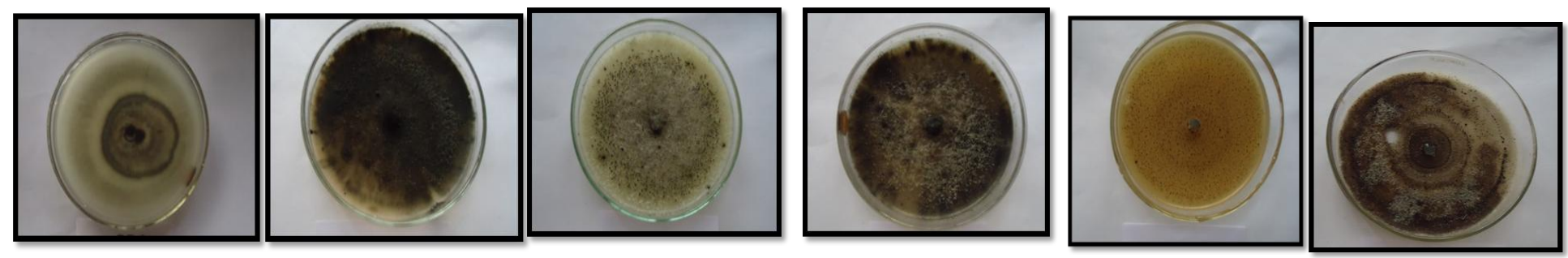

\begin{tabular}{|l|l|l|}
\hline $\begin{array}{l}\text { A:In PDA } \\
\text { medium }\end{array}$ & $\begin{array}{l}\text { B:In } \\
\text { CDASWS } \\
\text { medium }\end{array}$ & $\begin{array}{l}\text { C;In CDA } \\
\text { medium }\end{array}$ \\
\hline
\end{tabular}
D:In
CDASWL medium

\section{E:In PSA medium}

F:In OMA medium 
Plate.2a Spore produced in PSA medium Plate 2b: Acervuli produced in PSA medium
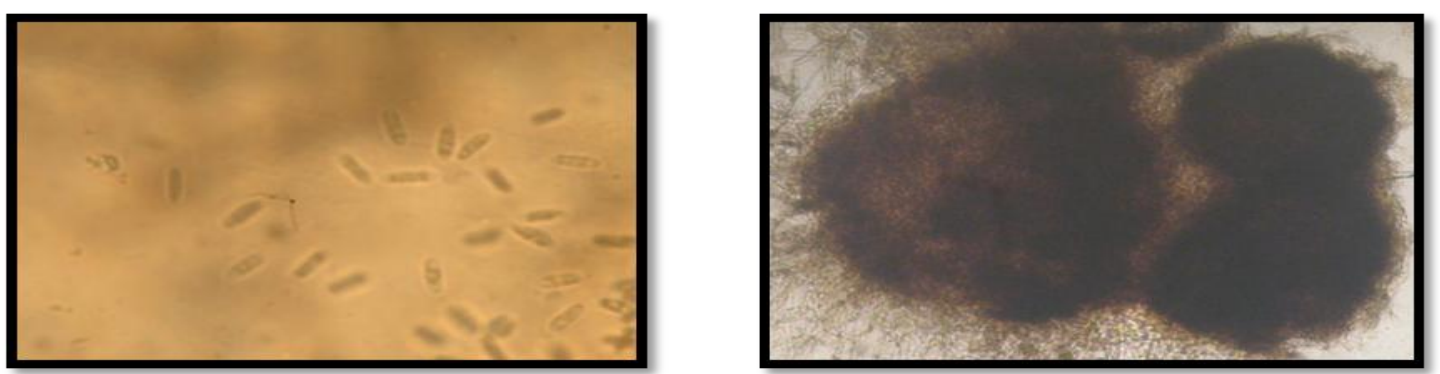

Plate.2c Spore produced in OMA medium Plate 2d: Acervuli and setae produced in OMA media
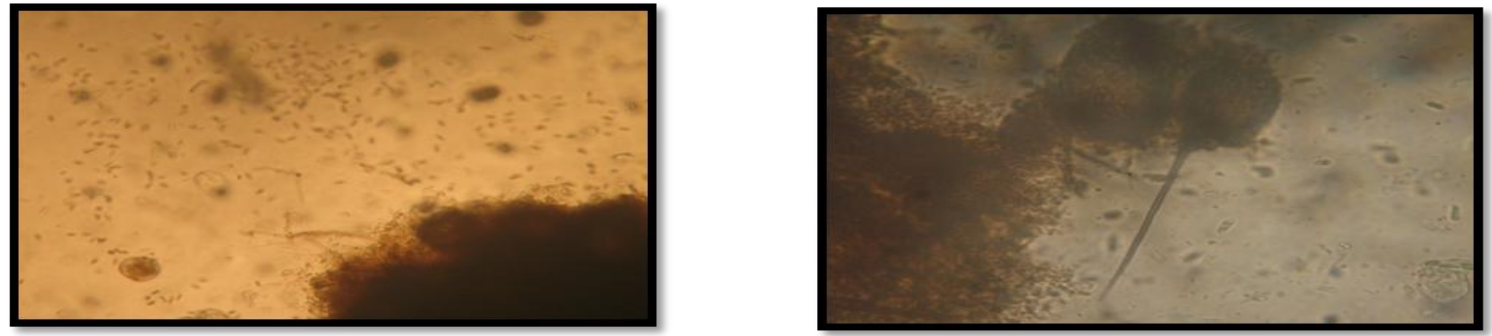

Different structures of $C$. acutatum produced in different carbon containing media
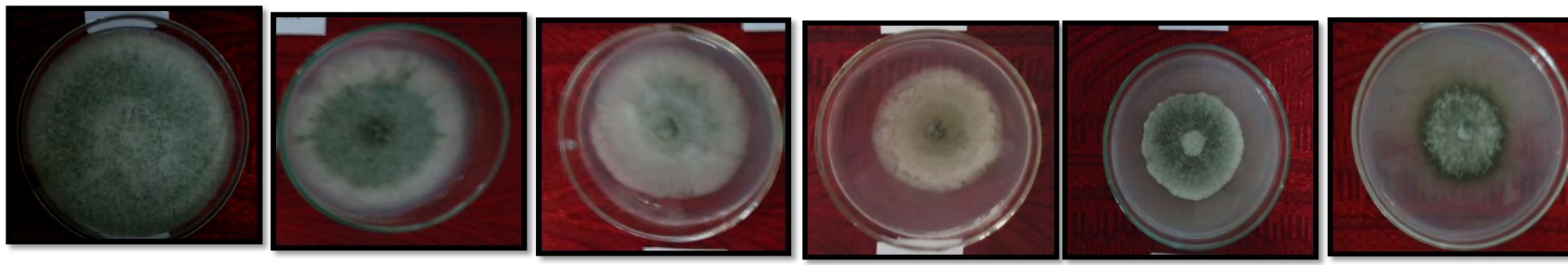

Plate.3 Blitox

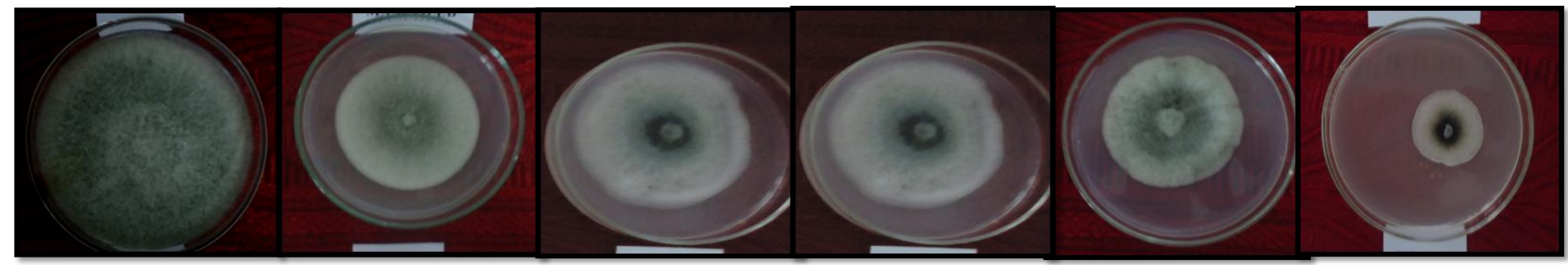

Plate.4 Mancozeb 

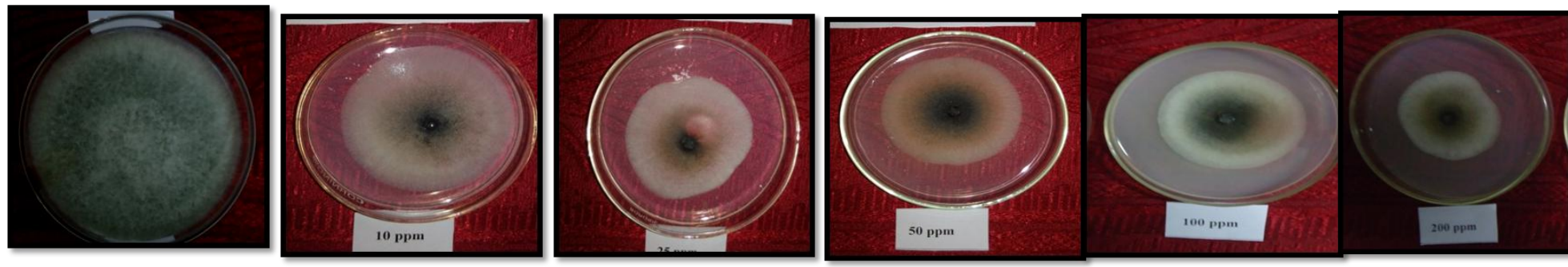

Plate.5 Chlorothalonil
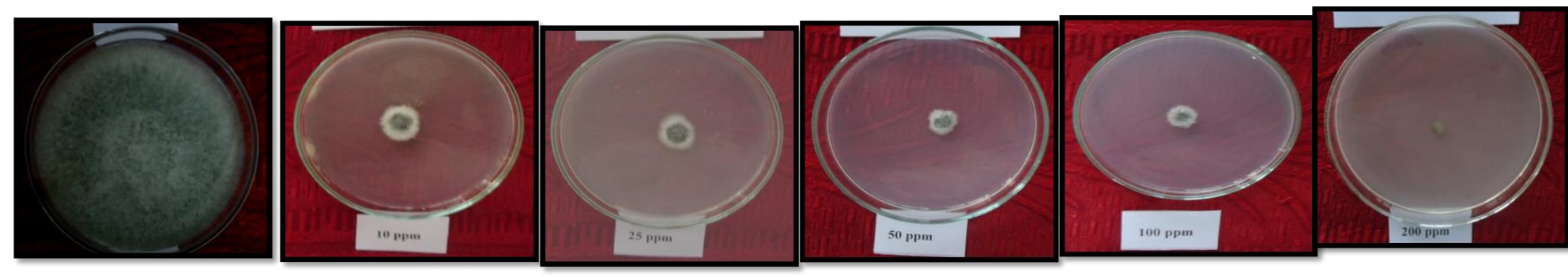

Plate.6 Difenoconazole

There were huge variations in acervuli sizes. Setae were a few dark brown, unbranched with pointed tips, $25.7-64.3 \mu$ (av. $44.9 \mu) \mathrm{x}$ $2.6-3.4 \mu$ (av. $2.9 \mu$ ). On the oat meal agar medium, the hyphal dimensions were 12.7$18.6 \mu \quad($ av. $15.7 \mu)$ and $5.2 \quad-$ $8.5 \mu($ av. $6.9 \mu)$.Conidia were hyaline (Plate $2 \mathrm{c})$, single celled, smooth or rough walled, sometimes guttulated, short cylindrical, both ends rounded measuring 13.9 -

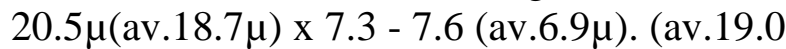
$\mu) \times$ 9.4-9.6 $\mu$ (av.9.5 $\mu$ ). ). The acervuli

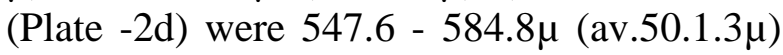

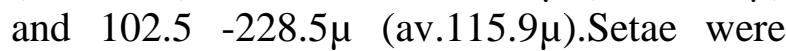
numerous, dark brown to black, 2 - 3 septate, unbranched, tapering /pointed which measured 32.8 - $44.5 \mu($ av. $37.4 \mu)$ x 5.9 $8.9 \mu($ avg.7.9).

\section{Fungicide sensitivity tests}

The bioassay of three non-systemic viz. Blitox (Plate:3a-e), Mancozeb (Plate:4a-e) and Chlorothalonil (Plate:5a-e) and one systemic fungicide Difenoconazole (Plate:6ae) using six different concentrations along with control were examined. It was found that Difenoconazole exhibited the highest percent inhibition and EC50 value $7.907 \mu / \mathrm{ml}$ in case of Colletotrichum acutatum and lowest percent inhibition in case of Blitox with a EC50 value of $223.4 \mu / \mathrm{ml}$.

\section{Acknowledgement}

First of all, I thank and praise Almighty God for providing me this opportunity and giving me courage and determination, to complete my work. I owe my deepest gratitude and regards to my honourable Chairman Prof. Birendranath Panja, Jayanta Saha and Dr. Gautam Mondal, Department of Plant Pathology. I also record my sincere reverence to Prof. Somnath Bhattacharya, Department of Plant Breeding and Genetics, Faculty of Agriculture, Bidhan Chandra Krishi Viswavidyalaya, Mohanpur, Nadia. Words and deeds are really insufficient to repay the unending support, help, cooperation and inspiration from my seniors and friends without their help it would not have been possible for me to complete my work. Finally, my deep and sincere gratitude to my family for their continuous and unparalleled love, help and support. I am grateful to my brother for always being there for me as a friend. I am 
forever indebted to my parents for giving me the opportunities and experiences that have made me who I am.

\section{References}

Bannerjee. A.Studies on pycnidia producing fungi of some ornamental plants grown under protected condition. M.Sc. thesis. Bidhan Chandra krishi Viswavidyalaya. 2016. p:52.

Horsefall, J.G. Principles of fungicidal action. Chronica Botanica Co., Altham, Mass, USA. 1956.

Katakam. M. Studies on acervulus producing fungi associated with selected greenhouse plants. M.Sc. thesis. Bidhan Chandra krishi Viswavidyalaya. 2016. p:40.

Kim, Y.K., Xiao, C.L. and Rogers, J.D. Influence of culture media and environmental factors on mycelial growth and pycnidial production of Sphaeropsis pyriputrescens. Mycologia. 2005. 97:25-32.

Kuhn, D.M. and Ghonnoum, M.A. Indoor mold, toxigenic fungi, and Stachybotrys chartarum: Infectious disease perspective. Clinical Microbiology Review. 2003. 16(1): 144-172.

Kumara, K.L.W. and Rawal, R.D. Influence of carbon, nitrogen, temperature and $\mathrm{pH}$ on the growth and sporulation of some Indian isolates of Colletotrichum gloeosporioides causing anthracnose disease of papaya (Carrica papaya L). Tropical Agricultural Research and Extension. 2008. 11: 7-12.

Northolt, M.D. and Bullerman, L.B. Prevention of mold growth and toxin. 1982.

Shervelle, E. G. Plant disease control. AVI Publishing Company, Inc. West. Post. Connecticut. 1979.

\section{How to cite this article:}

Tushnima Chaudhuri, Birendranath Panja and Jayanta Saha. 2018. Studies on Cultural, Morphological and Biochemical Aspects of Colletotrichum acutatum of Aglaonema using Various Carbon Sources. Int.J.Curr.Microbiol.App.Sci. 7(08): 2600-2606.

doi: https://doi.org/10.20546/ijcmas.2018.708.267 